
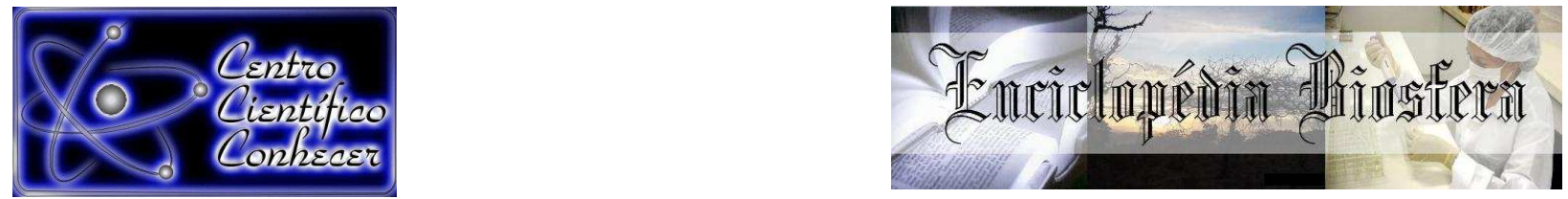

\title{
TÉCNICAS DE PROSPECÇÃO FITOQUÍMICA E SUA IMPORTÂNCIA PARA O ESTUDO DE BIOMOLÉCULAS DERIVADAS DE PLANTAS
}

\section{Nayane Peixoto Soares $^{1,2,3}$, Paula Lopes Santos ${ }^{2}$, Vanessa de Souza Vieira ${ }^{1,2}$, Vanessa de Souza Cruz Pimenta ${ }^{4}$, Eugênio Gonçalves de Araújo ${ }^{4}$}

1. Discente do programa de Pós-Graduação em Ciência Animal, nível doutorado, da

Escola de Veterinária e Zootecnia da Universidade Federal de Goiás,

(nayane peixoto@hotmail.com) Goiânia-Brasil;

2. Docente da Universidade Estadual de Goiás, Anápolis-Brasil;

3. Docente da Faculdade Metropolitana de Anápolis, Anápolis-Brasil.

4. Docente da Universidade Federal de Goiás, Goiânia-Brasil.

Recebido em: 03/10/2016 - Aprovado em: 21/11/2016 - Publicado em: 05/12/2016 DOI: 10.18677/EnciBio_2016B 094

\section{RESUMO}

As plantas medicinais são utilizadas desde a antiguidade e esse conhecimento tradicional é passado pelas gerações e podem orientar o estudo de moléculas bioativas, na pesquisa de princípios ativos ou na produção de medicamentos. Os metabólitos secundários são compostos químicos produzidos pelas plantas derivados do metabolismo primário da glicose e atuam na ecologia dos vegetais por meio de funções como atração de polinizadores e dispersores, defesa contra herbivoria e radiação entre outras. A fitoquímica atua no estudo dos metabólitos secundários e a prospecção fitoquímica irá detectar a presença desses e, com isso, orientar as demais etapas do estudo dos vegetais para produção de medicamentos e fitoterápicos. A prospecção pode ser realizada por testes de reações químicas ou por métodos cromatográficos. Os primeiros possuem baixo custo e são mais simples, os segundos necessitam de equipamentos dispendiosos e treinamento adequado para utilização, porém, são mais eficazes no estudo e podem ser utilizados nas demais etapas da investigação fitoquímica. Atualmente, os métodos mais utilizados são por reações químicas e investigações adicionais são realizadas juntamente com a prospecção fitoquímica. Tais estudos são importantes para a pesquisa farmacêutica, para a filogenética e principalmente na preservação dos recursos vegetais dos diferentes biomas brasileiros.

PALAVRAS-CHAVE: Farmacognosia, metabolismo vegetal, Plantas medicinais; Química experimental.

\section{PHITOCHEMICAL PROSPECTING TECHNIQUES AND THEIR IMPORTANCE TO THE STUDY OF BIOMOLECULAS DERIVED FROM PLANTS}

\begin{abstract}
Medicinal plants have been used since ancient times and that traditional knowledge is passed through generations and can guide the study of bioactive molecules in the active ingredients research or the production of medicines. Secondary metabolites are chemical compounds produced by plants derived from primary metabolism of glucose and act on the plant ecology through functions such as attracting pollinators
\end{abstract}


and dispersers, defense against herbivory and radiation among others. The phytochemical operates in the study of secondary metabolites and phytochemical prospection will detect the presence of these and, therefore, guide the remaining of the plant study stages for producing and herbal medicines. The prospection can be performed by chemical reactions tests or by chromatographic methods. The first have low cost and are simpler, the second require expensive equipment and adequate training to use, however, are most effective in the study and can be used in other stages of the phytochemical research. Currently, the methods used are by chemical reactions and additional investigation are carried out together with the phytochemical prospection. Such studies are important for pharmaceutical research, for phylogenetic and especially the preservation of plant resources of the different biomes.

KEYWORDS: Parmacognosy, medicinal plants, plant metabolism, experimental chemistry.

\section{INTRODUÇÃO}

Desde a antiguidade, as plantas são utilizadas pelo homem, não somente na agricultura como fonte de alimento, mas também com a finalidade medicinal. $O$ conhecimento popular sobre os efeitos biológicos de espécies vegetais é passado de geração em geração desde o início das civilizações (PEREIRA \& CARDOSO, 2012), o que tem direcionado as pesquisas para descobertas e aplicação das propriedades ativas vegetais, que são resultantes da produção de metabólitos secundários pelas plantas.

Os metabólitos secundários são compostos orgânicos produzidos pela célula vegetal como derivação do metabolismo primário. Não possuem função vital para a planta, mas garantem a sua sobrevivência, reprodução e dispersão por possuírem a capacidade de proteção contra raios UV, atração de polinizadores e dispersores de sementes, ação contra herbívoros, comunicação entre plantas, entre outras (OOTANI et al., 2013; WINK, 2013).

A fitoquímica tem importância no estudo dos metabólitos secundários, pois tem a finalidade de elucidar, caracterizar a estrutura química e avaliar as propriedades biológicas, além de registrar as substâncias provenientes das drogas vegetais (FILHO, 2010). A prospecção fitoquímica é um estudo preliminar que irá detectar a presença dos compostos de determinada planta e caracterizá-los. Por se tratar de um estudo básico para a investigação de plantas medicinais, é importante para orientar as etapas seguintes a serem realizadas na produção de fitoterápicos ou medicamentos de origem vegetal.

Deste modo, esta revisão de literatura tem por finalidade apresentar as técnicas de prospecção fitoquímica, a importância dessas para o estudo das drogas vegetais e o panorama atual da pesquisa nesta área nos últimos cinco anos.

\section{RECURSOS VEGETAIS COMO FONTE DE MOLÉCULAS BIOATIVAS}

As plantas constituem fonte de alimento, vestuário, artefatos para construção, energia e medicamento deste o início da humanidade. O homem, por meio da observação, foi capaz de reconhecer as propriedades bioativas das plantas, tanto terapêuticas quanto tóxicas, e com isso gerar conhecimento que foi passado por gerações ao longo do tempo. Assim, são utilizadas até hoje no tratamento e prevenção de enfermidades humanas e animais (CARVALHO, et al., 2014; LIMA et al., 2015; MORAIS et al., 2016; RODRIGUES et al., 2016). 
Além da utilização de plantas como alternativa terapêutica ser atualmente observada em um número cada vez maior de pessoas no mundo (LUZ et al., 2014), cerca de $25 \%$ dos medicamentos contém extratos vegetais em sua composição (LIMA et al., 2015) e um número maior são derivados de moléculas isoladas de drogas vegetais. Com isso, torna-se importante o empenho em realizar pesquisas em fitoquímica com o intuito de conhecer cada vez mais os princípios, as propriedades farmacológicas e toxicológicas, as formas de preparo e utilização seguras das plantas com potencial medicinal. Bem como o preparo adequado dos medicamentos, principalmente aquelas com o uso indicado pelo conhecimento tradicional (BESSA et al., 2013; LUZ et al., 2014; HYACIENTH \& ALMEIDA, 2015; LIMA et al., 2015).

O Brasil possui a maior biodiversidade vegetal do mundo e, como muitas espécies ainda não foram identificadas (RODRIGUES et al., 2016), não se conhece quais seriam suas potencialidades na medicina. $O$ interesse popular e o emprego de plantas medicinais e fitoterápicos está se consolidando no país. A política pública atual recomenda sua utilização na atenção primária à saúde (BESSA et al., 2013) e programas são desenvolvidos pelo Ministério da Saúde para incentivar, não somente o financiamento e a utilização de fitoterápicos pelo SUS, mas também para direcionar pesquisas que tornem este uso cada vez mais seguro (MARQUES et al., 2012).

Apesar de já ter estudado milhares de plantas e seus compostos ativos, ainda hoje são realizadas muitas pesquisas no intuito de conhecer novas moléculas e chegar à produção de fitoterápicos e fármacos de ação comprovada e utilização segura (CUNHA, 2014). Para isso, são seguidas etapas importantes que vão conduzir a investigação fitoquímica. Dentre estas etapas, está a busca pelo conhecimento tradicional, para indicar potencialidades terapêuticas na escolha da planta a ser estudada, a produção ou obtenção da planta, o preparo da droga vegetal, obtenção do extrato, a prospecção fitoquímica, a determinação química da estrutura do princípio ativo e a obtenção do medicamento.

A escolha da planta torna-se mais fácil quando é baseada em levantamentos etnobotânicos, informações populares e a bibliografia sobre o seu uso (BESSA et al., 2013; CUNHA, 2014). Após a escolha, deve ser feita uma identificação taxonômica por um profissional da Sistemática, por meio de chaves de identificação ou demais técnicas atuais. Essa identificação comprovará se o material coletado pertence à mesma espécie escolhida e auxiliará sobre a indicação de possíveis compostos químicos presentes na família botânica. Para realizar essa tarefa, é preciso fazer uma exsicata, que contenha um ramo representativo de folhas, caule, flores e, de preferência, frutos. Posteriormente à identificação, deposita-se em um herbário, com registro e informações sobre a localização geográfica, o bioma e a fitofisionomia, o clima, a hora de coleta, nome vernáculo, entre outros (SIMÕES et al. 2010; CUNHA, 2014).

A coleta do material a ser utilizado na pesquisa pode ser feita concomitante à do material destinado à produção da exsicata. Deste também devese registrar a localização, o horário e a data de coleta, para associação com a estação do ano (SIMÕES et al. 2010). É importante verificar o melhor horário para coletar o material a ser trabalhado, pois alguns metabólitos, como óleos voláteis, podem se perder com a variação climática e da luz ao longo do dia (OLIVEIRA et al., 2014). Precisa-se ainda fazer uma avaliação cautelosa antes de coletar, para evitar estruturas danificadas por parasitas e estruturas não interessantes para a pesquisa (CUNHA, 2014). 
O preparo do material vegetal tem como principal objetivo estabilizar enzimas para interromper o metabolismo que ocorre após a coleta e impedir que as análises não sejam afetadas por conter substâncias provenientes do fenecimento do vegetal (SIMÕES et al. 2010). Para isso, a matéria vegetal é seca em estufa de circulação de ar, método mais utilizado e eficaz, ou no ambiente ao sol, sombra ou misto, método que pode perder alguns compostos ou facilitar a proliferação de microrganismos. A secagem retira a água e impede a hidrólise e contaminação. A estabilização pode ser feita pela ação do calor ou desidratantes, como o etanol. Ambos irão desnaturar as estruturas proteicas das enzimas, no entanto, o etanol pode retirar alguns compostos importantes para as fases posteriores (SIMÕES et al. 2010; CUNHA, 2014).

Após a secagem e estabilização é feita a moagem, que reduz o material vegetal a partículas, aumentando a superfície de contato com o extrator na fase posterior. O tamanho das partículas vai depender do órgão a ser trabalhado; quanto mais rígido, mais deve-se reduzir a pó. São utilizados neste processo métodos como moinhos de facas, tesouras ou corte manual (SIMÕES et al. 2010).

A extração dos compostos químicos da matéria vegetal precisa ser adequada aos metabólitos secundários que a compõe ou que se deseja extrair, à polaridade do solvente, à temperatura, ao tempo de extração e ao custo disponível para o processo. Ainda que seja importante ter uma padronização dos extratos, ainda não se encontra disponível atualmente na Farmacopeia brasileira padronização adequada para grupos vegetais (RODRIGUES et al., 2016). O solvente desempenha função principal na extração, pois quanto mais seletivo, mais é possível extrair as substâncias desejadas também de forma direcionada (SIMÕES et al. 2010). No Quadro 1 encontram-se exemplos de solventes, com polaridades crescentes, mais utilizados em processos extrativos e os principais metabólitos secundários presentes nos extratos (SIMÕES et al. 2010; CUNHA, 2014).

QUADRO 1 - Principais solventes para extrair os metabólitos secundários, mencionados em escala crescente de polaridade.

\begin{tabular}{|l|c|}
\hline Solventes & Compostos preferencialmente extraídos \\
\hline Pentano, hexano, éter de petróleo. & $\begin{array}{c}\text { Furanocumarinas, hidrocarbonetos, } \\
\text { lipídeos, óleos essenciais, pigmentos, } \\
\text { ceras. }\end{array}$ \\
\hline Tolueno, diclorometano, clorofórmio. & $\begin{array}{c}\text { Bases livres de alcaloides, antraquinonas } \\
\text { livres, óleos voláteis, glicosídeos } \\
\text { cardiotônicos, óleos fixos, ceras. }\end{array}$ \\
\hline Acetato de etila, $n$-butanol. & $\begin{array}{c}\text { Flavonoides, cumarinas simples, } \\
\text { sapogeninas. }\end{array}$ \\
\hline Etanol, metanol. & Heterosídeos em geral. \\
\hline Soluções hidroalcoólicas, água. & Saponinas, taninos. \\
\hline Soluções aquosas acidificadas. & Alcaloides. \\
\hline Soluções aquosas alcalinizadas. & Saponinas. \\
\hline
\end{tabular}

Fonte: Adaptado de CUNHA (2014) e SIMÕES et al. (2010).

$\mathrm{O} \mathrm{pH}$ também é um fator importante do extrator, pois substâncias alcalinas, por exemplo, são extraídas por solventes ácidos e vice-versa. A maior parte dos compostos de interesse fitoquímico apresentam alguma solubilidade em misturas etanólicas ou metanólicas a $80 \%$, sendo por isso utilizadas frequentemente (SIMÕES et al. 2010; CUNHA, 2014). São empregadas, de forma suplementar aos 
solventes, as técnicas de extrações a frio, infusão, turbolização, decocção, extração sob refluxo, em aparelho de Soxhlet.

Para proceder ao estudo fitoquímico, é feita uma prospecção dos metabólitos secundários presentes no extrato. Algumas técnicas realizam a pesquisa direta no órgão vegetal, mas a maior parte utiliza o extrato com o extrator ou o elimina antecipadamente. Esta ação é baseada em testes químicos de coloração ou precipitação, e/ou testes cromatográficos (SIMÕES et al. 2010; CUNHA, 2014; OLIVEIRA et al., 2014).

No caso da prospecção fitoquímica e o conhecimento popular ou bibliográfico, indicar uma atividade farmacológica da planta em estudo, devem ser feitas investigações posteriores com o intuito de isolar os compostos que atuam na função terapêutica específica. $O$ isolamento é feito na maior parte dos casos por fracionamento cromatográfico, que inclui numerosas técnicas complexas, como cromatografia de fase gasosa, de fase líquida, de fase supercrítica, eletroforese capilar, entre outros; ou mais simples, como cromatografia em papel, em camada delgada, em coluna aberta, de exclusão, entre outras técnicas que separam em função do tamanho molecular (CUNHA, 2014).

Após o isolamento dos compostos, é feita a elucidação da estrutura molecular de todos os constituintes isolados. São utilizadas técnicas como espectro de absorção no ultravioleta, no infravermelho, espectrometria de massa, espectrometria de ressonância magnética nuclear e de Raman, entre outras, que irão fornecer dados sobre os grupos químicos orgânicos presentes e os tipos e quantidades de ligações, por exemplo. Se o composto for isolado pela primeira vez, sua estrutura é confirmada pela síntese química da molécula (CUNHA, 2014).

Todos esses passos descritos levam à produção do fármaco ou fitoterápico. Para chegar a ter a sua eficácia comprovada e uso permitido, esse novo produto deverá passar por testes farmacológicos e toxicológicos em fases experimentais, pré-clínicas e clínicas, utilizando-se de recursos enzimáticos, culturas celulares, testes clínicos controlados em animais e humanos (SIMÕES et al. 2010; CUNHA, 2014; OLIVEIRA et al., 2014).

Nesse contexto, é fundamental a sistematização de técnicas e procedimentos adequados para identificar inúmeras moléculas que são potencialmente princípios ativos valiosos à saúde humana e animal (CARVALHO et al., 2014). Também é notória a importância dos estudos fitoquímicos preliminares, no intuito de investigar os metabólitos presentes, avaliar se a ação relatada é coerente a esses compostos, verificar o teor de determinados princípios ativos e orientar a pesquisa aplicada para a produção final do fármaco. É ainda importante conhecer os produtos do metabolismo celular vegetal e suas estruturas químicas para que sejam eficazes todas as etapas do estudo dos fármacos vegetais.

\section{METABOLISMO VEGETAL: METABÓLITOS PRIMÁRIOS E SECUNDÁRIOS}

O metabolismo vegetal é responsável pela formação, acúmulo e degradação de substâncias celulares de natureza orgânica. Esta biossíntese é classificada em metabolismo primário, responsável por produzir nutrientes vitais para o organismo vegetal; e metabolismo secundário, que produz substâncias derivadas dos metabólitos primários e atuam na defesa contra herbívoros e infecções por microrganismos proteção contra radiação UV, atração de polinizadores, entre outras funções (SIMÕES et al. 2010).

Os metabólitos primários são os carboidratos, lipídeos, peptídeos, proteínas, etc. Já os metabólitos secundários agregam especificidade ao organismo 
vegetal, pois são diversos, como por exemplo, os alcaloides, flavonoides, taninos, cumarinas, entre outros, e seus subtipos. A presença e concentração depende de características do solo, índice de radiação, duração do ciclo circadiano, clima e demais características do ambiente que exigem do vegetal uma resposta de defesa, sinalização entre organismos, reprodução ou dispersão (MATOS, 2009; SIMÕES et al. 2010; PAES et al., 2013; CUNHA, 2014; OLIVEIRA et al., 2014; MENDONÇA et al., 2015). Por isso, desempenham uma função ecológica importante como estratégia de vida (PAES et al., 2013).

A diversidade e a composição química dos metabólitos secundários despertam o interesse da pesquisa farmacêutica, agronômica e alimentícia, pois são estes os princípios ativos vegetais hoje utilizados na produção de droga vegetal e seus derivados, controle de pragas e alimentos de valores nutricionais (CUNHA, 2014; OLIVEIRA et al., 2014).

Os metabólitos secundários são produzidos a partir da glicose, que é um produto do metabolismo primário. A glicose pode seguir duas vias no metabolismo secundário: a produção de ácido chiquímico ou acetil co-enzima A (acetil CoA). Consequentemente, há metabólitos secundários que derivam do ácido chiquímico pelas vias do triptofano, fenilalanina/tirosina e ácido gálico, ou que derivam da acetil CoA, pelo ciclo do ácido cítrico, via do mevalonato e por condensação; e, por fim, aqueles que derivam da ligação entre unidades do ácido chiquímico e acetil CoA, produzidos por ambos os derivados da glicose. Há ainda os metabólitos secundários heterosídeos, que possuem moléculas de açúcar ligadas e as agliconas, que não possuem estas moléculas (SIMÕES et al. 2010).

As funções biológicas dos metabólitos secundários são extensivamente estudadas devido a potencialidade de sua utilização na medicina humana e veterinária. É importante destacar os principais metabólitos e suas funções já desvendadas. Os alcaloides possuem propriedade antibacteriana, antifúngica, antiplasmódica e antitumoral (SILVA et al., 2007; HENRIQUE et al., 2010) pela capacidade de desestabilizar as membranas biológicas. Também apresentam a capacidade de inibir a síntese de DNA e RNA ao se ligarem aos ácidos nucleicos e se intercalarem à dupla hélice (SIMÕES et al. 2010). São exemplos de alcaloides utilizados atualmente a morfina (analgésico), a escopolamina (anticolinérgicos), teofilina (diuréticos), vincristina (antitumorais), codeína (antitussígenos) (BESSA et al., 2013).

Os flavonoides são os compostos mais numerosos nas Angiospermas e possuem atividades anti-inflamatórias, antialérgicas, antiulcerogênicas, antivirais, antiproliferativas, antioxidantes, hepatoprotetoras, antitrômbicas e anticarcinogênicas (SIMÕES et al. 2010; BESSA et al., 2013). Os taninos são compostos fenólicos que possuem a propriedade de se complexar com íons metálicos e com macromoléculas como proteínas e polissacarídeos, por isso desempenham função de antioxidante, protetor contra herbívoros e microrganismos. São utilizados como antissépticos, adstringentes, antidiarreicos, cicatrizantes de feridas, queimaduras e inflamações, devido à capacidade de precipitar proteínas (SIMÕES et al. 2010; BESSA et al., 2013; LUZ et al., 2014). Tem ainda a capacidade de estimular células fagocíticas (BESSA et al., 2013).

Os terpenos compõem alguns óleos essenciais e, por isso, atuam na atração de polinizadores. Possuem ainda ação inseticida, antimicrobiana, hepatoprotetora, analgésica, anti-inflamatória, antimicrobiana, hemolítica, entre outras (SIMÕES et al. 2010; LUZ et al., 2014). Os triterpenos possuem efeito antiinflamatório, analgésico, cardiovascular e antitumorais (IKEDA et al., 2008). 
As saponinas têm a capacidade de diminuir a tensão superficial da água e, in vitro, causam hemólise eritrociária. Alteram a permeabilidade de membrana pela ação lipofílica e complexação com lipídeos e proteínas da membrana celular, o que causa destruição das células. Por isso, apresentam características tóxicas (LUZ et al., 2014). Desempenham ainda funções moluscida, antifúngica, antimicrobiana, antiparasitária, antiviral, citotóxica e antitumoral (BESSA et al., 2013).

Os compostos fenólicos têm a capacidade de neutralizar radicais livres inibindo o risco de doenças cardiovasculares, diabetes, tumores e processos inflamatórios. As cumarinas são utilizadas para dermatoses, psoríase, vitiligo e outras doenças de pele, são ainda, anticoagulante e laxativo, como as antraquinonas. As catequinas são antioxidantes, termogênicas, anti-inflamatória e anticarcinogênica. Os esteroides possuem funções cardiotônicas, ativadoras do anabolismo, precursores da vitamina D e anticoncepcionais (BESSA et al., 2013).

A obtenção desses metabólitos vegetais para produção de fitoterápicos pode ser feita por meio de extrativismo de plantas as quais é sabido possuir os compostos desejados e quais as condições climáticas e estação do ano tais compostos estarão disponíveis. No entanto, são também produzidas culturas vegetais e de tecidos para a aquisição controlada dos princípios ativos vegetais (CARVALHO et al., 2014).

\section{PROSPECÇÃO FITOQUÍMICA}

As plantas possuem diversas substâncias químicas que estão presentes em todas as espécies e outras que são características de grupos botânicos ou intraespecíficas, produtos do metabolismo primário e secundário, respectivamente. As variações destes compostos estão submetidas à influência do clima, da composição do solo e do período vegetativo, entre outros (CUNHA, 2014).

A análise fitoquímica preliminar tem por objetivo caracterizar os componentes químicos presentes nas plantas, produtos do metabolismo secundário vegetal. Esses metabólitos servirão como marcadores químicos da espécie, ou até mesmo da região que são encontradas. Ao conhecer a composição química da droga vegetal a ser trabalhada, pode-se delinear com mais clareza os melhores métodos para a extração e os bioensaios aos quais deverá ser submetida para 0 isolamento de princípios ativos na produção de fármacos e fitoterápicos (BESSA et al., 2013; CARVALHO et al., 2014; LUZ et al., 2014; SILVA et al., 2016). Nesse contexto, a análise fitoquímica ganha mais importância quando não tem todos os estudos químicos com a espécie de interesse popular, para verificar a qualidade da droga vegetal e também fornecer dados úteis para 0 conhecimento da biodiversidade e filogenética das plantas (BESSA et al., 2013). São, portanto, estudos preliminares e básicos dentro da Fitoquímica, Farmacognosia e produção de medicamentos.

Os métodos e técnicas empregados na prospecção fitoquímica variam de acordo com a tecnologia disponível. Existem métodos rápidos e de baixo custo e métodos que exigem equipamentos que nem sempre estão presentes em laboratórios de pesquisa vegetal. Rotineiramente, são realizados testes com reações químicas de coloração e precipitação em tubos de ensaios e placas de toques. Todavia, são também feitas detecções e fracionamentos cromatográficos com reagentes distintos, acompanhados de testes farmacológicos simples (SIMÕES et al., 2010; CUNHA, 2014). 
Os testes qualitativos por reações químicas são rápidos e de baixo custo e tem relevância por possibilitar traçar o perfil químico do vegetal (BESSA et al., 2013). Porém, o trabalho de caracterização fitoquímica envolve também uma combinação de ferramentas quantitativas e específicas, que demonstrem não só a classe, mas a estrutura e qualidade das moléculas encontradas (CARVALHO et al., 2014), e outros testes de pureza e qualidade da droga preconizados na Farmacopeia brasileira, como teor de cinzas, umidade, granulometria e características organolépticas (CARDOSO et al., 2013).

\section{MÉTODOS POR REAÇÕES QUÍMICAS}

Métodos que se baseiam na reação química entre os compostos esperados nos extratos vegetais e regentes detectores conhecidos são os métodos preliminares de prospecção fitoquímica mais utilizados. São também os mais antigos, pois um dos primeiros roteiros para estes estudos data de 1850, proposto por Stas e modificado por Otto (SIMÕES et al., 2010).

Existem diversos métodos prospectivos que utilizam reagentes detectores, baseados na precipitação de proteínas, formação de espumas e mudanças de coloração. Destes, são muito utilizados os testes propostos por SIMÕES et al., (2010) e MATOS (2009). Alguns testes comumente utilizados para detectar os respectivos metabólitos secundários são apresentados de forma sumária no Quadro 2.

O reagente de Wagner, utilizado na detecção de Alcaloides, é formado por iodo-iodeto de potássio; o reagente de Mayer é composto por solução de iodomercurato de potássio; reagente de Dragendorff por iodo-bismutato de potássio; e reagente de Bertrand por ácido silício-túngstico (o ácido inorgânico mais utilizado). O ácido pícrico é utilizado como ácido orgânico (SIMÕES et al., 2010; CUNHA, 2014).

Para realizar as reações dos compostos antraquinônicos, é necessário obtê-los na forma reduzida, por meio da ação do peróxido de hidrogênio. Por ser uma reação apolar, é direcionada à detecção de agliconas antraquinônicas, por isso é preciso realizar a hidrólise anteriormente. Já as cumarinas, em solução alcalina têm o seu anel lactônico rompido e assim desenvolve a coloração amarela na observação sob UV (360 nm), podendo ser revertida com adição de solução ácida (SIMÕES et al., 2010; CUNHA, 2014). Antes da realização de detecção de triterpenos e esteroides, o etanol deve ser eliminado e é recomendável desengordurar a solução com éter de petróleo (SIMÕES et al., 2010; CUNHA, 2014).

Os resultados para flavonoides podem ser ocultos pela presença de pigmentos na amostra, o que pode ser evitado com éter de petróleo para extraí-los. A reação caracteriza compostos que contém um núcleo a-benzoprina pela coloração vermelha a laranja. Tipos de flavonoides podem ser detectados, como as flavonas e flavonóis, que se dissolvem em ácido sulfúrico concentrado (cor amarelo escuro), já chalconas e auronas apresentam resultados com cores alaranjado ao vermelho (SIMÕES et al., 2010; CUNHA, 2014). Os heterosídeos cardiotônicos com desoxioses apresentam resultados positivos para o teste de Keller-Killiani e as lactonas insaturadas $\alpha$ e $\beta$ são positivas para Kedde, de Baljet e de Legal (CUNHA, 2014). 
QUADRO 2 - Principais testes baseados em colorimetria, precipitação e espuma.

\begin{tabular}{|c|c|c|}
\hline Metabólito Secundário & Testes e reagentes & Resultados positivos \\
\hline Alcaloides & $\begin{array}{l}\text { Reações de precipitação: } \\
\text { Reagentes de Wagner; de } \\
\text { Mayer; } \quad \text { Dragendorff; } \\
\text { Bertrand; ácidos orgânicos e } \\
\text { inorgânicos. }\end{array}$ & Formação de precipitados. \\
\hline $\begin{array}{l}\text { Compostos antraquinônicos } \\
\text { livres }\end{array}$ & 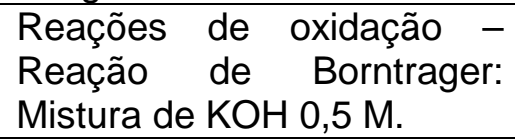 & $\begin{array}{l}\text { Formação de precipitados } \\
\text { de base vermelha. }\end{array}$ \\
\hline Cumarinas & $\begin{array}{lll}\text { Observação } & \text { sob } & \text { luz } \\
\text { ultravioleta. }\end{array}$ & $\begin{array}{l}\text { Fluorescência azul brilhante } \\
\text { ou verde. }\end{array}$ \\
\hline $\begin{array}{l}\text { Triterpenos e esteroides } \\
\text { livres }\end{array}$ & $\begin{array}{l}\text { Reação de Liebermann- } \\
\text { Burchard; } \\
\text { anidro acético - ácido } \\
\text { sulfúrico concentrado. } \\
\text { Reação de Salkowski: } \\
\text { Clorofórmio e ácido sulfúrico } \\
\text { concentrado. }\end{array}$ & $\begin{array}{l}\text { Esteroides: coloração azul, } \\
\text { verde, } \quad \text { vermelho } \quad \text { (coloração } \\
\text { alaranjado } \quad \text { (compo); } \\
\text { mutável com o tempo } \\
\text { Triterpenos: vermelha ou } \\
\text { amarela (coloração estável). }\end{array}$ \\
\hline Flavonoides & $\begin{array}{l}\text { Teste de Cianidina ou } \\
\text { Shinoda: } \\
\text { Ácido clorídrico concentrado } \\
\text { e magnésio em pó. }\end{array}$ & $\begin{array}{l}\text { Coloração laranja ou } \\
\text { vermelha. }\end{array}$ \\
\hline $\begin{array}{l}\text { Glicosídeos/Heterosídeos } \\
\text { cardiotônicos e Lactonas } \\
\text { sesquiterpênicas }\end{array}$ & $\begin{array}{l}\text { Reações de Kedde; de } \\
\text { Baljet; de Legal; e de Keller- } \\
\text { Killiani. }\end{array}$ & $\begin{array}{l}\text { Presença de núcleo } \\
\text { esteroidal. }\end{array}$ \\
\hline $\begin{array}{l}\text { Heterosídeos } \\
\text { cianogenéticos }\end{array}$ & $\begin{array}{l}\text { Ácido sulfúrico e fita de } \\
\text { papel impregnada de picrato } \\
\text { de sódio. }\end{array}$ & $\begin{array}{l}\text { Coloração } \quad \text { vermelho } \\
\text { castanha na fita de papel. }\end{array}$ \\
\hline Oses e holosídeos & Reagente de Molisch. & $\begin{array}{l}\text { Formação de duas fases e } \\
\text { um anel de cor púrpura } \\
\text { entre as duas. }\end{array}$ \\
\hline Saponinas & $\begin{array}{l}\text { Agitação intensa. } \\
\text { Reação hemolítica. }\end{array}$ & $\begin{array}{l}\text { Formação de espuma } \\
\text { persistente. } \\
\text { Hemólise. }\end{array}$ \\
\hline Polifenóis & $\begin{array}{l}\text { Cloreto férrico (reação muito } \\
\text { genérica). }\end{array}$ & $\begin{array}{l}\text { Coloração azul ou verde } \\
\text { azulada. }\end{array}$ \\
\hline Taninos & $\begin{array}{l}\text { Reação de precipitação: } \\
\text { Gelatina, pó de pele, metais } \\
\text { pesados, sais de alcaloides. } \\
\text { Reação de Stiasny (taninos } \\
\text { condensados). }\end{array}$ & Formação de precipitado. \\
\hline Açúcares redutores & $\begin{array}{l}\text { Reação de Benedict: } \\
\text { Sulfato cúprico. }\end{array}$ & \\
\hline
\end{tabular}

Fonte: Adaptado de CUNHA (2014); SIMÕES et al., (2010) e MATOS (2009).

Os resultados para heterosídeos cianogênicos apresentam a coloração devido à hidrólise do heterosídeo pelo ácido sulfúrico, e com isso, a liberação do ácido cianídrico, que origina a cor vermelho-castanha na fita em papel (CUNHA, 2014). Nos testes para oses e holosídeos forma-se o anel púrpura devido à desidratação dos glucídeos (SIMÕES et al., 2010; CUNHA, 2014).

BESSA et al., (2013) utilizaram tais testes para prospecção fitoquímica de algumas plantas do Cerrado e observaram os resultados para saponinas (formação 
de espuma abundante e persistente); fenóis e taninos (formação de precipitado e mudança de coloração - azul nos extratos etanólico de $M$. urundeuva e $S$. obovatum e verde nos extratos etanólicos e metanólico das demais espécies); catequinas (coloração vermelha); esteroides e triterpenos; cumarina (fluorescência azulada progressiva e forte); antraquinonas (formação de precipitado de coloração vermelha); alcaloides (precipitado laranja avermelhado para reação de Mayer e Bouchardat e vermelho tijolo na reação de Dragendorff); flavonóides (precipitado de coloração vermelha).

HYACIENTH \& ALMEIDA (2015) utilizaram uma reação chamada de Pascova A e Pascova para detecção de ácidos orgânicos na espécie Pseudoxandra cuspidata; e observaram a presença de compostos fenólicos pela utilização de ácido férrico. RODRIGUES et al., (2015) realizaram a prospecção fitoquímica da espécie Erythroxylum suberosum e verificaram a presença de saponina por meio do teste de agitação. Utilizaram a reação de Shinoda, oxalobórica e reação com hidróxidos e verificaram a presença de flavonoides pelo aparecimento de coloração vermelha, fluorescência evidente e coloração amarela para os respectivos testes. Observaram também a presença de taninos pela formação de precipitado e coloração enegrecida em reação ao cloreto férrico, e realizaram os testes com fluorescência para cumarinas, evidenciando sua presença.

SOUSA et al., (2015) realizaram testes de prospecção para análise fitoquímica do própolis da abelha jandaíra. Para tal, utilizaram cloreto férrico para fenóis simples e taninos; teste de acidulação e alcalinização para detecção de antocianinas, antocianidinas e flavonóides; teste de acidulação e alcalinização com aquecimento para detecção de antocianinas, antocianidinas e flavonoides; leucoantocianidinas, catequinas e flavonas; reagente de Lieberman-Burchard para esteróides e triterpenóides; formação de espuma persistente pela agitação, para saponinas. Além disso, relataram o grau de presença do metabólito secundário no extrato pela intensidade da reação estabelecida como forte $(+++)$, médio $(++)$, fraco (+) e ausente (-), seguindo o que foi proposto por MATOS (2009).

Esses testes são muito utilizados em trabalhos básicos de prospecção fitoquímica, como os supracitados, pois apresentam um baixo custo, por não exigir a utilização de equipamentos tecnológicos. Outrossim, são eficientes para detectar a presença dos metabólitos secundários de interesse e nortear a pesquisa aplicada sobre a droga vegetal. No entanto, é preciso que a partir desses trabalhos sejam realizados outros que avaliem os potenciais das plantas analisadas e direcionem para produção de fitoterápicos e medicamentos, produtos de controle biológico ou associem a trabalhos filogenéticos.

Muitas vezes, já no estudo preliminar, essas técnicas são associadas a outras, que podem dosar a quantidade de algum metabólito. Como exemplos, podem ser citados: doseamento de fenóis e taninos total e teor de flavonoides (RODRIGUES et al, 2015); testes bioquímicos de atividades enzimáticas como a capacidade antioxidante por meio de reações do DPPH (ABE et al., 2014; MORAIS et al., 2016; SILVA et al., 2016); associação a testes in vitro e in vivo para medir a atividade antibacteriana (CARVALHO et al., 2014; HYACIENTH \& ALMEIDA, 2015; SOUSA et al., 2015; AQUINO et al., 2016; SILVA et al., 2016), atividade leishmanicida (LIMA et al., 2015), anti-radicalar (SOUSA et al., 2015), toxicidade (HYACIENTH \& ALMEIDA, 2015) e atividade citotóxica (SILVA et al., 2016). Esse tipo de estudo demonstra a ação dos metabólitos encontrados na prospecção por meio de outros testes. 
Estudos também são realizados para inventariar outros aspectos do vegetal ou da droga, como estudos farmacognósticos completos (MATOS et al., 2014; RODRIGUES et al, 2015), aspectos estruturais (PAES et al., 2013; MENDONÇA et al., 2015), controle de qualidade na obtenção do extrato (CARDOSO et al., 2013) e caracterização físico-química (MARQUES et al., 2012).

\section{MÉTODOS CROMATOGRÁFICOS}

Os métodos cromatográficos de análise não se limitam apenas à detecção dos metabólitos secundários; na maioria das vezes em que são utilizados, são destinados também ao fracionamento, isolamento e purificação de substâncias. Por ser um processo de análise imediata, caracteriza-se por realizar os procedimentos supracitados com menor trabalho, tempo reduzido e maior precisão (LUZ et al., 2014). A cromatografia analítica é utilizada para identificação e análise de misturas e substâncias isoladas e a cromatografia preparativa atua no isolamento de compostos (SIMOES et al., 2010).

A cromatografia consiste em uma fase estacionária, que pode estar contida em uma coluna ou ser uma superfície plana; e por uma fase móvel, que contém um solvente e a amostra a ser analisada. Essa é chamada de fase móvel porque irá eluir pela fase estacionária (a amostra analisada junto ao solvente) e será separada em diferentes níveis. Os compostos de uma mistura podem ser separados com base nos coeficientes de partição entre dois solventes (um contido na fase móvel e outro na estacionária); por adsorção dos componentes da fase móvel aos da fase estacionária baseado na afinidade química; por troca iônica dos compostos da fase móvel e resinas com grupos funcionais da fase estacionária; e pelo tamanho dos componentes da fase móvel que passam por um gel (SIMÕES et al., 2010). Dessa forma, a técnica envolve, na sequência, a montagem de uma coluna ou placa com a disposição da fase estacionária, aplicação da amostra, eluição (passagem) do solvente/amostra pela fase estacionária, revelação da placa com a visualização das diferentes zonas de separação e extração das substâncias retidas na fase estacionária (SIMÕES et al., 2010).

O que diferencia uma técnica cromatográfica da outra são os tipos de equipamentos utilizados e os materiais utilizados como fase estacionária. Dentre estas, as mais comuns são a cromatografia gasosa (CG), a cromatografia em camada delgada (CCD), a cromatografia líquida em coluna e de alta eficiência (CLAE ou HPLC). A CG é utilizada na detecção e separação misturas que contenham compostos voláteis e pode ser acoplada a um sistema de esctrometria de massas (CG/EM) ou detector de ionização de chama, aumentando a eficiência na separação e identificação de substâncias (SIMÕES et al., 2010; CUNHA, 2014). A CCD é utilizada tanto para analisar os extratos brutos quanto para verificar a eficiência de separação de compostos, podendo ainda ser utilizada para transformação de ácidos graxos em ésteres metílicos, que são subsequentemente analisados por CG (CUNHA, 2014).

A cromatografia líquida em coluna é uma das técnicas mais utilizadas para separação e isolamento de compostos presentes em drogas vegetais, por permitir utilizar diferentes colunas e combinações de fases móveis e estacionárias. Já a CLAE é uma técnica mais dispendiosa, pois utiliza colunas com a fase estacionária constituída por partículas finas, entre 3 a $10 \mu \mathrm{m}$, de diferentes formatos e densidades, que oferecem maior resistência ao fluxo da fase móvel, o que 
necessita de maior pressão para que a eluição ocorra a uma velocidade razoável (SIMÕES et al., 2010).

VECHIA et al (2016) verificaram em seu trabalho que a CLAE é eficiente no isolamento e validação de moléculas provenientes de extratos vegetais, e por isso amplamente utilizada, por permitir que dados qualitativos e quantitativos sejam obtidos para amostras de polaridades variadas em uma única eluição. Além disso, é possível analisar por várias formas de detecção e ter a especificidade e o conteúdo de informações por ensaio aumentadas.

Uma outra técnica utilizada por CARVALHO et al. (2014) foi a espectrofometria na faixa do ultravioleta e visível (UV-VIS). Esta técnica permite as análises qualitativas e quantitativas de misturas, por possibilitar a observação de perfis no espectro que mostram a presença dos constituintes da mistura. Por isso, é uma técnica amplamente utilizada nos últimos 50 anos.

As técnicas descritas são muito eficientes não apenas na prospecção fitoquímica, mas também no estudo geral das drogas vegetais e na produção de fitoterápicos e/ou medicamentos, por permitir que os princípios ativos sejam, não somente identificados como nos métodos químicos, mas também isolados, quantificados e validados. Porém, é necessário maior investimento em equipamentos e treinamentos de recursos humanos, o que torna tais métodos mais onerosos.

\section{PANORAMA ATUAL DA PESQUISA DE PROSPECÇÃO FITOQUÍMICA}

Muito se tem feito para conhecer os princípios ativos vegetais, pois a utilização de plantas medicinais é tão antiga, quanto eficaz e deve ser cada dia mais segura. Para isso, os estudos em prospecção fitoquímica são basilares e tem sido realizados diversos estudos nos últimos cinco anos. À guisa de exemplo, pode-se discorrer sobre algumas das pesquisas, que representam a importância desse tipo de investigação para a descoberta de novos fármacos.

Dos estudos realizados com plantas do Cerrado, foram pesquisados por meio dos testes reativos, os metabólitos secundários das espécies Lafoensia pacari; Plathymenia reticulata; Terminalia fagifolia; Vochysia haenkeana; Vellozia squamata e Galactia glaucescens. Como conclusão dos estudos, foi atribuído o efeito leishmanicida aos compostos encontrados (LIMA et al., 2015).

Foram também estudadas as espécies Anacardium othonianum; Brosimum gaudichaudii; Cecropia pachystachya; Hymenaeae courbaril; Genipa americana; Myracrodruon urundeuva; Siparuna guianensis; Stryphnodendron obovatum e Vernonia brasiliana, indicadas pelo uso popular em uma comunidade rural no Tocantins (BESSA et al., 2013).

Para ater-se a um exemplo local, partes de exemplares da espécie Erythroxylum suberosum, coletadas no município de Goiânia (RODRIGUES et al, 2015); e folhas e raízes da espécie Spiranthera odoratissima (CARDOSO et al., 2013), foram analisadas com 0 intuito de estabelecer seus padrões farmacognósticos. Nestes estudos foram evidenciadas somente as classes de metabólitos secundários, dados condizentes com as possibilidades de identificação dos métodos utilizados. Fato semelhante ocorreu com a espécie Himatanthus drasticus (LUZ et al., 2014), que teve os compostos analisados por meio de Cromatografia em Camada Delgada (CCD) com o extrato fracionado, o que gerou como resultado também as classes dos metabólitos presentes nesta espécie, sem ter isolado algum composto específico, como permite a técnica. 
Das plantas originárias da Caatinga, foram analisadas as plantas Cnidoscolus phyllacanthus (MORAIS et al., 2016) e Sideroxylon obtusifolium (AQUINO et al., 2016) por meio dos testes reativos e a planta Opuntia cochenillifera (SILVA et al., 2016) utilizando tanto desses testes quanto da CCD. Tais técnicas foram utilizadas para identificar a classe dos compostos presentes e a CCD foi utilizada na produção do extrato vegetal.

Foram feitos estudos também com plantas não endêmicas do Brasil, com distribuição neotropical ou em faixas mais amplas de distribuição, como no caso das espécies Piptadenia gonoacantha (CARVALHO et al., 2014); alho, Momordica charantia L. e casca de manga (LINS et al., 2012). Esses vegetais foram investigados por meio de CCD com a finalidade de verificar se os compostos presentes exercem algum efeito sobre o controle da podridão peduncular em manga.

Também dignos de nota são os estudos com as espécies Pseudoxandra cuspidata (HYACIENTH \& ALMEIDA, 2015); Costus spicatus (PAES et al., 2013); Bauhinia forficata (MARQUES et al., 2012); Psychotria colorata e Psychotria hoffmannseggiana (MENDONÇA et al., 2015), analisadas por testes de reação química; e Solidago chilensis (VECHIA et al., 2016), estudada por Cromatografia Líquida de Alta Eficiência (CLAE). Esta última teve o composto quercitrina, um flavonoide, isolado.

A CCD foi utilizada para estudar os metabólitos presentes nos resíduos de café seco e fermentado por Monascus ruber (BRITO et al., 2012) e, nesse sentido, o produto Geoprópolis da abelha jandaíra teve também sua prospecção fitoquímica realizada (SOUSA et al., 2015), porém, por testes de reações químicas.

As metodologias mais utilizadas nos trabalhos supracitados foram as propostas por MATOS (2009) em seu compêndio de diversas edições (oito artigos) e SIMÕES (2010) (dois artigos). Foram utilizadas outras metodologias como a de SHARAPIN (2000). Alguns autores não citaram a fonte de suas metodologias. No Quadro 3 pode-se verificar os metabólitos secundários detectados, por meio dessas metodologias, nas plantas estudadas nos últimos cinco anos.

QUADRO 3 - Metabólitos secundários detectados nas espécies estudadas nos últimos cinco anos

\begin{tabular}{|c|c|c|}
\hline Espécies & $\begin{array}{l}\text { Família } \\
\text { Botânica }\end{array}$ & Metabólitos Secundários \\
\hline $\begin{array}{l}\text { Allium sp. (bulbo } \\
\text { comercial de alho) }\end{array}$ & Liliaceae & $\begin{array}{l}\text { Monoterpenoides, sesquiterpenoides, } \\
\text { triterpenoides e esteroides. }\end{array}$ \\
\hline $\begin{array}{l}\text { Anacardium othonianum } \\
\text { Rizz. }\end{array}$ & Anacardiaceae & Saponinas, fenóis, taninos e catequina. \\
\hline & & $\begin{array}{c}\text { Caule: fenóis, flavononas, leucoantocianinas, } \\
\text { catequinas, flavononas e alcaloides. }\end{array}$ \\
\hline Bauhinia forficata Link & Caesalpiniaceae & $\begin{array}{l}\text { Folhas: proantocianidinas, } \\
\text { leucoantocianidinas, triterpenos, esteróides, } \\
\text { flavonóides e açúcares redutores. }\end{array}$ \\
\hline $\begin{array}{l}\text { Brosimum gaudichaudii } \\
\text { Trécul. }\end{array}$ & Moraceae & $\begin{array}{l}\text { Saponinas, catequinas, antraquinonas, } \\
\text { alcalóides e flavonóides. }\end{array}$ \\
\hline $\begin{array}{l}\text { Cecropia pachystachya } \\
\text { T. }\end{array}$ & Cecropiacea & $\begin{array}{c}\text { Alcalóides, flavonóides, triterpenos, esteróides } \\
\text { e catequinas. }\end{array}$ \\
\hline \multirow{2}{*}{$\begin{array}{l}\text { Cnidoscolus } \\
\text { phyllacanthus (müll. } \\
\text { Arg.) Pax \& k.hoffm. }\end{array}$} & \multirow[t]{2}{*}{ Euphorbiaceae } & $\begin{array}{l}\text { Folhas: flavonas, flavonóis e xantonas, fenóis, } \\
\text { flavonoides e xantonas. }\end{array}$ \\
\hline & & \\
\hline
\end{tabular}




\begin{tabular}{|c|c|c|}
\hline \multirow[t]{3}{*}{ Espécies } & $\begin{array}{c}\text { Família } \\
\text { Botânica }\end{array}$ & Metabólitos Secundários \\
\hline & & saponinas. \\
\hline & & $\begin{array}{l}\text { Raízes: flavonoides do tipo flavonas, flavonóis } \\
\text { e xantonas, triterpenóides pentacíclicos livres, } \\
\text { saponinas. }\end{array}$ \\
\hline \multirow[b]{3}{*}{$\begin{array}{l}\text { Costus spicatus (Jacq.) } \\
\text { Sw. }\end{array}$} & \multirow[b]{3}{*}{ Costaceae } & $\begin{array}{c}\text { Raíz e Rizoma: Saponinas, Heterosideos } \\
\text { Cianogênicos, ácidos voláteis, } \\
\text { leucoantocianidinas e flavononas. }\end{array}$ \\
\hline & & $\begin{array}{l}\text { Caule: taninos, saponinas, Heterosideos } \\
\text { Cianogênicos, ácidos voláteis Fenóis, } \\
\text { Leucoantocianidinas, flavononas, e alcaloides. }\end{array}$ \\
\hline & & $\begin{array}{l}\text { Folhas: taninos, saponinas, Heterosideos } \\
\text { Cianogênicos, ácidos voláteis, fenóis, } \\
\text { catequinas, flavononas e alcaloides. }\end{array}$ \\
\hline $\begin{array}{l}\text { Erythroxylum suberosum } \\
\text { A. St.-Hilaire }\end{array}$ & Erythroxylaceae & $\begin{array}{l}\text { Flavonóides, taninos, cumarinas, saponinas e } \\
\text { resinas. }\end{array}$ \\
\hline $\begin{array}{l}\text { Galactia glaucescens } \\
\text { Kunth }\end{array}$ & Fabaceae & $\begin{array}{c}\text { Flavonoides, Triterpenoides, Esteróides, } \\
\text { Saponinas, Compostos Fenólicos, Taninos e } \\
\text { Chalconas. }\end{array}$ \\
\hline Genipa americana L. & Rubiaceae & $\begin{array}{c}\text { Taninos e fenóis, alcalóides, saponinas, } \\
\text { esteróides e triterpenos. }\end{array}$ \\
\hline $\begin{array}{l}\text { Geoprópolis da abelha } \\
\text { jandaíra. }\end{array}$ & - & $\begin{array}{c}\text { Taninos hidrolisáveis, flavonóides das classes } \\
\text { das flavonas e flavonóis, xantonas e } \\
\text { triterpenos pentacíclicos livres. }\end{array}$ \\
\hline $\begin{array}{l}\text { Himatanthus drasticus } \\
\text { Plumel }\end{array}$ & Apocynaceae & $\begin{array}{l}\text { Taninos, alcaloides, saponinas, triterpenos, } \\
\text { cumarinas, heterosídeos flavônicos, esteroides } \\
\text { e saponinas. }\end{array}$ \\
\hline Hymenaeae courbaril L. & Caesalpinaceae & $\begin{array}{l}\text { Triterpenos, esteroides, flavonóides, fenóis e } \\
\text { taninos. }\end{array}$ \\
\hline Lafoensia pacari St.-Hil. & Lythraceae & $\begin{array}{c}\text { Antraquinonas, Flavonoides, Esteróides, } \\
\text { Saponinas, Cumarinas, Compostos Fenólicos } \\
\text { e Taninos. }\end{array}$ \\
\hline $\begin{array}{l}\text { Mangifera sp. (Casca de } \\
\text { Manga Tommy Atkins) }\end{array}$ & Anacardiaceae & $\begin{array}{c}\text { Monoterpenoides e sesquiterpenoides, } \\
\text { triterpenoides e esteroides, flavonoides, } \\
\text { açúcares redutores, fenilpropanoglicosídeos e } \\
\text { xantonas. }\end{array}$ \\
\hline Momordica charantia L. & Cucurbitaceae & $\begin{array}{l}\text { Mono e sesquiterpenoides, triterpenos e } \\
\text { esteroides, saponinas e flavonoides. }\end{array}$ \\
\hline $\begin{array}{l}\text { Myracrodruon urundeuva } \\
\text { Fr. All. }\end{array}$ & Anacardiaceae & $\begin{array}{c}\text { Alcalóides, fenóis e taninos, catequinas e } \\
\text { saponinas. }\end{array}$ \\
\hline $\begin{array}{l}\text { Opuntia cochenillifera (L) } \\
\text { Mill }\end{array}$ & Cactaceae & $\begin{array}{l}\text { Fenois, taninos, flavonoides, Flavononas, } \\
\text { flavonois, xantonas, esteroides livres, } \\
\text { saponinas, alcaloides, antraquinonas, } \\
\text { antronas. }\end{array}$ \\
\hline $\begin{array}{l}\text { Piptadenia gonoacantha } \\
\text { (Mart.) J. F. Macbr. }\end{array}$ & Fabaceae & $\begin{array}{c}\text { Compostos fenólicos, flavonóides, taninos e } \\
\text { cumarinas. }\end{array}$ \\
\hline $\begin{array}{l}\text { Plathymenia reticulata } \\
\text { Benth. }\end{array}$ & Fabaceae & $\begin{array}{l}\text { Flavonoides, Triterpenoides, Esteróides, } \\
\text { Compostos Fenólicos e Taninos. }\end{array}$ \\
\hline $\begin{array}{l}\text { Pseudoxandra cuspidata } \\
\text { Maas }\end{array}$ & Annonaceae & $\begin{array}{c}\text { Ácidos orgânicos, alcaloides e compostos } \\
\text { fenólicos. }\end{array}$ \\
\hline Psychotria colorata & Rubiaceae & $\begin{array}{c}\text { Caule: fenóis, flavononas, leucoantocianinas, } \\
\text { catequinas, flavononas e alcaloides. }\end{array}$ \\
\hline
\end{tabular}




\begin{tabular}{|c|c|c|}
\hline Espécies & $\begin{array}{c}\text { Família } \\
\text { Botânica }\end{array}$ & Metabólitos Secundários \\
\hline $\begin{array}{l}\text { (Willd. ex R. \& S.) Müll. } \\
\text { Arg }\end{array}$ & & $\begin{array}{c}\text { Folhas: taninos, flavonas, flavonoides, } \\
\text { xantonas, chalconas, flavonóis, } \\
\text { leucoantocianinas, catequinas, flavononas e } \\
\text { alcaloides. }\end{array}$ \\
\hline \multirow{2}{*}{$\begin{array}{l}\text { Psychotria } \\
\text { hoffmannseggiana (R. e } \\
\text { S.) Mull. Arg. }\end{array}$} & \multirow[b]{2}{*}{ Rubiaceae } & $\begin{array}{c}\text { Caule: fenóis, flavononas, chalconas, } \\
\text { leucoantocianinas, catequinas, flavonas e } \\
\text { alcaloides. }\end{array}$ \\
\hline & & $\begin{array}{c}\text { Folhas: fenóis, taninos, flavonas, chalconas, } \\
\text { flavononas e alcaloides. }\end{array}$ \\
\hline $\begin{array}{l}\text { Resíduos de Café Seco } \\
\text { e fermentado por } \\
\text { Monascus Ruber }\end{array}$ & Rubiaceae & $\begin{array}{l}\text { Saponinas, triterpenos e esteroides, } \\
\text { cumarinas, taninos, flavonoides e alcaloides }\end{array}$ \\
\hline $\begin{array}{l}\text { Sideroxylon obtusifolium } \\
\text { (Roem. \& Schult.) T.D. } \\
\text { Penn. }\end{array}$ & Sapotaceae & $\begin{array}{c}\text { Fenóis, Taninos Pirogálicos, Flavonoides, } \\
\text { Catequinas e alcaloides. }\end{array}$ \\
\hline $\begin{array}{l}\text { Siparuna guianensis } \\
\text { Aublet }\end{array}$ & Siparunaceae & $\begin{array}{c}\text { Alcalóides, terpenos, cumarina, fenóis, taninos } \\
\text { e flavonóides. }\end{array}$ \\
\hline $\begin{array}{l}\text { Solidago chilensis } \\
\text { Meyen }\end{array}$ & Asteraceae & Elevado teor de flavonoides, quercitrina. \\
\hline & & $\begin{array}{l}\text { Raízes: alcaloides, cumarinas, açúcares } \\
\text { redutores, amido e saponinas. }\end{array}$ \\
\hline $\begin{array}{l}\text { Spiranthera odoratissima } \\
\text { A. St.-Hil. }\end{array}$ & Rutaceae & $\begin{array}{c}\text { Folhas: fenóis, taninos, açúcares redutores, } \\
\text { cumarinas, flavonoides, triterpernos, } \\
\text { esteroides, antocianinas, saponinas e } \\
\text { antraquinona. }\end{array}$ \\
\hline $\begin{array}{l}\text { Stryphnodendron } \\
\text { obovatum Benth. }\end{array}$ & Mimosaceae & $\begin{array}{l}\text { Saponinas, taninos e fenóis, esteróides e } \\
\text { triterpenos, alcalóides e flavonóides. }\end{array}$ \\
\hline $\begin{array}{l}\text { Terminalia fagifolia Mart. } \\
\text { et Zucc }\end{array}$ & Combretaceae & $\begin{array}{c}\text { Antraquinonas, Flavonoides, Triterpenoides, } \\
\text { Saponinas, Cumarinas, Compostos Fenólicos } \\
\text { e Taninos. }\end{array}$ \\
\hline Vellozia squamata Pohl & Velloziaceae & $\begin{array}{c}\text { Flavonoides, Esteróides, Saponinas e } \\
\text { Cumarinas. }\end{array}$ \\
\hline $\begin{array}{l}\text { Vernonia brasiliana (L.) } \\
\text { Druce }\end{array}$ & Asteraceae & Fenóis e Taninos, flavonoides. \\
\hline $\begin{array}{l}\text { Vochysia haenkeana } \\
\text { Mart. }\end{array}$ & Vochysiaceae & $\begin{array}{l}\text { Antraquinonas, Flavonoides, Triterpenoides, } \\
\text { Esteróides, Saponinas, Cumarinas e Taninos. }\end{array}$ \\
\hline
\end{tabular}

Dos trabalhos analisados, foram utilizados extratos aquosos (LINS et al., 2012; PAES et al., 2013), extratos metanólicos (MARQUES et al., 2012; BESSA et al., 2013; AQUINO et al., 2016), etanólico (SILVA et al., 2007; BESSA et al., 2013; CARDOSO et al., 2013; MENDONÇA et al., 2015; VECHIA et al., 2016), hidroalcóolico (BRITO et al., 2012; PAES et al., 2013; CARVALHO et al., 2014; LIMA et al., 2015; SOUSA et al., 2015; VECHIA et al., 2016), e fracionado (LUZ et al., 2014; MATOS et al., 2014). A escolha do extrato irá depender dos compostos que se deseja extrair; porém o extrato alcóolico e hidroalcóolico são os mais utilizados, por possuírem a capacidade de extrair grande quantidade de metabólitos secundários (SIMÕES et al., 2010; OLIVEIRA et al., 2014; CUNHA, 2014).

Alguns autores realizaram trabalhos complementares junto à prospecção fitoquímica como o teste de toxicidade em Artemia salina Leach e atividade antibacteriana (HYACIENTH \& ALMEIDA, 2015); avaliação do potencial antioxidante do extrato (MORAIS et al., 2016); avaliação da atividade antibacteriana, citotóxica e 
antioxidante (SILVA et al., 2016); avaliação da atividade anti-inflamatória tópica e antibacteriana (AQUINO et al., 2016); avaliação da capacidade leishmanicida (LIMA et al., 2015); determinação de parâmetros farmacognósticos e doseamento de flavonoides totais (RODRIGUES et al, 2015); controle de qualidade e obtenção de extratos (CARDOSO et al., 2013); atividade antibacteriana (CARVALHO et al., 2014); caracterização físico-química (MARQUES et al., 2012); efeitos do extrato do resíduo fermentado no metabolismo de Camundongos Apo E (BRITO et al., 2012); toxicidade in vitro e atividade anti-radicalar e antibacteriana (SOUSA et al., 2015).

\section{CONSIDERAÇÕES FINAIS}

O caminho a ser percorrido para a produção de um medicamento derivado de moléculas vegetais ou fitoterápico perpassa por etapas que envolvem a escolha de plantas com indicativo de efeitos específicos, o conhecimento das classes de metabólitos secundários, 0 isolamento dos princípios ativos e determinados testes. Nesse sentido, a prospecção fitoquímica atua na pesquisa básica dessa produção, pois orienta o estudo ao indicar quais compostos estão presentes nas plantas de interesse. Além de também poder ser utilizada em caracterização fitoquímica para outras finalidades, como a filogenética.

Os métodos hoje utilizados para trabalhos desse gênero variam em complexidade e valores, de acordo com o recurso disponível e os objetivos a se atingir podem ser empregados testes de reações químicas de coloração e precipitação, testes cromatográficos ou ambos combinados. Nas pesquisas atuais, apesar dos métodos cromatográficos serem os mais tecnológicos, ainda se utiliza, na maior parte das pesquisas, os métodos por reatividade química.

Algumas pesquisas não se atêm apenas à prospecção fitoquímica, mas realizam ensaios que demonstram as propriedades dos metabólitos ou às suas aplicações, ainda são feitas caracterizações físico-químicas e elucidações moleculares mais aplicadas, e outras pesquisas se baseiam no conhecimento popular para orientar a busca pelos metabólitos secundários.

É importante que estudos desses modelos sejam realizados para que possa não apenas atuar na fabricação de produtos bioativos, mas que também mostre a importância em se preservar os recursos vegetais dos diversos biomas brasileiros, pois, como se vê, em todos eles encontram-se plantas e outras substâncias com potenciais terapêuticos.

\section{REFERÊNCIAS}

ABE, S. Y.; SILVA, S. M.; POSSAMAI, J. C.; NAKASHIMA, T. Prospecção fitoquímica, teor de flavonoides totais e capacidade antioxidante de Campomanesia xanthocarpa Mart. ex O. Berg (Myrtaceae). Revista Brasileira de Farmácia, v. 9, n. 2, p. 01-14, 2014. doi: 10.5216/ref.v11i2.19967.

AQUINO, P.; FIGUEREDO, F. G.; PEREIRA, N.; NASCIMENTO, E.; MARTIN, A.; VERAS, H.; OLIVEIRA, C.; FERREIRA, S.; LEANDRO, L.; SILVA, M.; MENEZES, I. Avaliação da atividade anti-inflamatória tópica e antibacteriana do extrato metanólico das folhas de Sideroxylon obtusifolium. Acta biológica Colombiana, v. 21, n. 1, p. 131-140, 2016. Disponível em: <http://dx.doi.org/10.15446/abc.v21n1.48170>. doi: 10.15446/abc.v21n1.48170. 
BESSA, N. G. F. D.; BORGES, J. C. M.; BESERRA, F. P.; CARVALHO, R. H. A.; PEREIRA, M. A. B.; FAGUNDES, R.; CAMPOS, S. L.; RIBEIRO, L. U.; QUIRINO, M. S.; CHAGAS JUNIOR, A. F.; ALVES, A. Prospecção fitoquímica preliminar de plantas nativas do cerrado de uso popular medicinal pela comunidade rural do assentamento vale verde - Tocantins. Revista Brasileira de Plantas Medicinais, v. 15 n. 4, p. 692-707, 2013. Disponível em: <http://dx.doi.org/10.1590/S151605722013000500010>. doi: 10.1590/S1516-05722013000500010.

BRITO, L. F.; QUEIRÓS, L. D.; PELUZIO, M. C. G.; RIBEIRO, S. M. R.; MATTA, S. L. P.; QUEIROZ, J. H. Efeito dos Resíduos de Café Seco e Fermentado por Monascus ruber no Metabolismo de Camundongos Apo E. Arquivos Brasileiros de Cardiologia, v. 99, n. 2, p. 747-754, 2012. Disponível em: <http://dx.doi.org/10.1590/s0066-782x2012005000068>. doi: 10.1590/s0066$782 \times 2012005000068$.

CARDOSO, C. R. P.; SALGADO, H. G. N.; VILEGAS, W. Controle de qualidade e obtenção de extratos de espécies vegetais do cerrado brasileiro com potencial etnofarmacológico. Ciência \& Tecnologia, v. 5, supl. 2013. Disponível em: <http://www.citec.fatecjab.edu.br/index.php/files/article/view/166/pdf>.

CARVALHO, C. A.; SANTANA, G. S.; AMARO, M. O. F.; LIMA, L. M.; PIRES, F. B.; PRÁ, V. D.; CARDOSO, S. A.; ROSA, M. B.; OLIVEIRA, L. L. Aspectos químicos e atividade antibacteriana de Piptadenia gonoacantha (Fabaceae). Ciência e Natura, v. 36, n. 2, p. 732-744, 2014. Disponível em: <http://dx.doi.org/10.5902/2179460X13456>. doi. 10.5902/2179460X13456.

CUNHA, A. (org). Farmacognosia e Fitoquímica. 4aㅗ ed. Lisboa: Fundação Calouste Gulbenkian. 2014.

FILHO, R. B. Contribuição da Fitoquímica Para o Desenvolvimento de um País Emergente. Quimica Nova, v. 33, n. 1, 2010. Disponível em: <http://dx.doi.org/10.1590/S0100-40422010000100040>. doi: 10.1590/S010040422010000100040.

HENRIQUE, M. C.; NUNOMURA, S. M.; POHLIT, A. M. Alcaloides indólicos de cascas de Aspidosperma vargasii e A. desmanthum. Química Nova, v. 33, n. 2, p. 284-287, 2010. Disponível em: <http://dx.doi.org/10.1590/S010040422010000200010>. doi: 10.1590/S0100-40422010000200010.

HYACIENTH, D. C.; ALMEIDA, S. S. M. S. Estudo fitoquímico, toxicidade em Artemia salina Leach e atividade antibacteriana de Pseudoxandra cuspidata Maas. Biota Amazônia, v. 5, n. 4, p. 4-7, 2015. Disponível em: <http://dx.doi.org/10.18561/2179-5746/biotaamazonia.v5n4p4-7>. doi: $10.18561 / 2179-5746$.

IKEDA, Y.; MURAKAMI, A.; OHIGASHI, H. Ursolic acid: na anti- and proinflammatory triterpenoid. Molecular Nutrition \& Food Research, v. 52, p. 26-42, 2008. Disponível em: <http://www.ncbi.nlm.nih.gov/pubmed/18203131>. doi: 10.1002/mnfr.200700389. 
LINS, S. R. O.; OLIVEIRA, S. M. A.; XAVIER, H. S.; RANDAU, K. P. Prospecção fitoquímica de extratos de plantas e controle da podridão peduncular em manga. Revista Brasileira de Ciências Agrárias, v.7, n.1,p.97-103, 2012. Disponível em: $<$ http://www.agraria.pro.br/sistema/index.php?journal=agraria\&page=article\&op=view Article\&path\%5B\%5D=agraria_v7i1a1633>. doi:10.5039/agraria.v7i1a1633.

LIMA, P. C.; SANTOS, M. G.; CALABRESE KS, SILVA ALA, ALMEIDA F. Avaliação da capacidade leishmanicida de espécies vegetais do Cerrado. Revista de Patologia Tropical, v. 44, n. 1, p. 45-55, 2015. Disponível em: <http://dx.doi.org/10.5216/rpt.v44i1.34800>. doi: 10.5216/rpt.v44i1.34800.

LUZ, H. S.; SANTOS, A. C. G.; LIMA, F. C.; MACHADO, K. R. G. Prospecção fitoquímica de Himatanthus drasticus Plumel (Apocynaceae), da mesorregião leste maranhense. Revista Brasileira de Plantas Medicinais, v. 16, n. 3, p. 657-662, 2014. Disponível em: <http://dx.doi.org/10.1590/1983-084x/12_114>. doi: 10.1590/1983-084x/12_114.

MARQUES, G. S.; LYRA, M. A. M.; PEIXOTO, M. S.; MONTEIRO, R. P. M.; LEÃO, W. F.; XAVIER, H. S.; SOARES, L. A. L.; ROLIM NETO, P. J. Caracterização fitoquímica e físico- química das folhas de Bauhinia forficata Link coletada em duas regiões brasileiras. Revista de Ciências Farmacêuticas Básica e Aplicada, v. 33, n. $1, \quad$ p. 57-62, $2012 . \quad$ Disponível em: <https://doaj.org/article/341031c9415d4411bab5a89f12b0eeda>. doi: 341031c9415d4411bab5a89f12b0eeda.

MATOS, F. J. D. A. Introdução à fitoquímica experimental. Fortaleza: edições UFC, 2009.

MATOS, L. G.; FIUZA, T. S.; TRESVENZOL, L. M. F.; REZENDE, M. H.; BARA, M. T. F.; SILVEIRA, E. M.; COSTA, E. A.; PAULA, J. R. Estudo farmacognóstico de folhas e raízes da Spiranthera odoratissima A. St.-Hil. (Rutaceae). Revista Brasileira de Plantas Medicinais, v. 16, n. 3, p. 574-584, 2014. Disponível em: <http://dx.doi.org/10.1590/1983-084X/13_045>. doi: 10.1590/1983-084X/13_045.

MENDONÇA, A. C. A. M.; SILVA, M. A. P.; ANDRADE, A. O.; AlENCAR, S. R.; MACHADO, M. E. Prospecção fitoquímica de Psychotria colorata (Willd. Ex. R. \& S.) Müll. Arg. E P. Hoffmannseggiana (R. \& S.) Müll. Arg. Caderno de Cultura e Ciência, v. 13, n. 2, p. 7-16, 2015. doi:10.14295/cad.cult.cienc.v13i2.853

MORAIS, N. R. L.; OLIVEIRA NETO, F. B.; MELO, A. R.; BERTINI, L. M.; SILVA, F. F. M.; ALVES, L. A. Prospecção fitoquímica e avaliação do potencial antioxidante de Cnidoscolus phyllacanthus (müll. Arg.) Pax \& k.hoffm. Oriundo de apodi - RN. Revista Brasileira de Plantes Medicinais, v. 18, n. 1, p. 180-185, 2016. <Disponível em: http://dx.doi.org/10.1590/1983-084X/15_058>. doi: 10.1590/1983084X/15_058.

OLIVEIRA, F.; AKISUE, G.; AKSUE, M. K. Farmacognosia: identificação de drogas vegetais. $2^{\mathrm{a}}$ ed. São Paulo: Atheneu. 2014. 
OOTANI, M. A.; AGUIAR, R.W.; RAMOS, A. C. C.; BRITO, D. R.; SILVA, J. B.; CAJAZEIRA, J. P. Use of Essential Oils in Agriculture. Journal of Biotechnology and Biodiversity, v. 4, n. 2, p. 162-174, 2013 . Disponível em: $<$ https://www.researchgate.net/publication/296484575_Use_of_Essential_Oils_in_Ag riculture>.

PAES, L. S.; MENDONÇA, M. S.; CASAS, L. L. Aspectos Estruturais e Fitoquímicos de partes vegetativas de Costus spicatus (Jacq.) Sw. (Costaceae). Revista Brasileira de Plantas Medicinais, v. 15, n. 3, p. 380-390, 2013. Disponível em: <http://dx.doi.org/10.1590/S1516-05722013000300011>. doi: 10.1590/S151605722013000300011.

PEREIRA, R. J.; CARDOSO, M. G. Vegetable secondary metabolites and antioxidants benefits. Journal of Biotechnology and Biodiversity, v. 3, n. 4, p. 146-152, 2012. Disponível em: <http://www.ncbi.nlm.nih.gov/pubmed/21067179>. doi: $10.1021 /$ jf1037745.

RODRIGUES, F. A.; PIMENTA, V. S. C.; BRAGA, K. M. S.; ARAÚJO, E. G. A. Obtenção de extratos de plantas do cerrado. Enciclopédia Biosfera, v.13, n. 23, p. 870-887, $2016 . \quad$ Disponível em: <http://www.conhecer.org.br/enciclop/2016a/agrarias/obtencao\%20de\%20extatos.pd f>. doi: 10.18677/Enciclopedia_Biosfera_2016_075.

RODRIGUES, G. A.; SOUZA, W. C.; GODINHO, M. G. C.; FERREIRA, H. D.; VILA VERDE, G. M. Determinação de parâmetros farmacognósticos para as folhas de Erythroxylum suberosum A. St.-Hilaire (Erythroxylaceae) coletadas no município de Goiânia, GO. Revista Brasileira de Plantas Medicinais, v. 17, n. 4, p. 1159-1168, 2015. Disponível em: <http://dx.doi.org/10.1590/1983-084X/14_114>. doi: 10.1590/1983-084X/14_114.

SHARAPIN, N. Fundamentos de tecnologia de produtos Fitoterápicos. Santesé de Bogotá, Colômbia: CYTED; 2000.

SILVA, A. L. L.; ARAUJO, M. G. S.; BASTOS, M. L. A.; BERNARDO, T. H. L.; OLIVEIRA, J. F. S.; SILVA-JUNIOR, E. F.; SANTOS-JUNIOR, P. F. S.; ARAUJO, M. V.; ALEXANDRE-MOREIRA, M. S.; ARAÚJO-JÚNIOR, J. X.; VERISSIMO, R. C. S. S. Avaliação da atividade antibacteriana, citotóxica e antioxidante da espécie vegetal Opuntia cochenillifera (L.) Mill. Revista Brasileira de Plantas Medicinais, v. 18, n. 1, p. 307-315, 2016. Disponível em: <http://dx.doi.org/10.1590/1983084X/15_145>. doi: 10.1590/1983-084X/15_145.

SILVA, D. B.; MATOS, M. F. C.; NAKASHITA, S. T.; MISU, C. K.; YOSHIDA, N. C.; CAROLLO, C. A.; FABRI, J. R.; MIGLIO, H. S.; SIQUEIRA, J. M. Isolamento e avaliação da atividade citotóxica de alguns alcalóides oxaporfínicos obtidos de annonaceae. Química Nova, v. 30, n. 8, p. 1809-1812, 2007. Disponível em: <http://dx.doi.org/10.1590/S0100-40422007000800004>. doi: 10.1590/S010040422007000800004. 
SIMÕES, C. M. O.; SCHENKEL, E. P.; GOSMANN, G.; MELLO, J. C. P.; MENTZ, L. A.; PETROVICK, P. R. Farmacognosia da planta ao medicamento. $6^{\mathrm{a}}$ ed. Porto Alegre/Florianópolis: Editora UFRS/ UFS. 2010.

SOUSA, D. M. N.; OLINDA, R. G.; MARTINS, C. G.; ABRANTES, M. R.; COELHO, W. A. C.; SILVA, J. B. A.; MORAIS, S. M.; BATISTA, J. S. Prospecção fitoquímica, toxicidade in vitro e avaliação das atividades anti-radicalar e antibacteriana da geoprópolis da abelha jandaíra. Acta Veterinaria Brasilica, v. 9, n. 2, p. 134-140, 2015. Disponível em: <http://dx.doi.org/10.21708/avb.2015.9.2.4784>. doi: 10.21708/avb.2015.9.2.4784.

VECHIA, C. A. D.; MORAIS, B.; SCHONELL, A. P.; DIEL, K. A. P.; FAUST, C.; MENIN, C.; GOMES, D. B.; ROMAN JUNIOR, W. A. Isolamento químico e validação analítica por cromatografia líquida de alta eficiência de quercitrina em Solidago chilensis Meyen (Asteraceae). Revista Brasileira de Plantas Medicinais, v. 18, n. 1 , p. 288-296, 2016. Disponível em: <http://dx.doi.org/10.1590/1983084X/15_128>. doi: 10.1590/1983-084X/15_128.

WINK, M. Evolution of secondary metabolites in legumes (Fabaceae). South African Journal of Botany, v. 89, p. 164-175, 2013. Disponível em: <http://dx.doi.org/10.1016/j.sajb.2013.06.006>. doi: 10.1016/j.sajb.2013.06.006. 